Revista de

Contabilidade e

Organizações

www.rco.usp.br
DOI: http://dx.doi.org/10.11606/rco.v9i23.75590
Journal of

Accounting and

Organizations

\title{
Valor de mercado e fundamentos contábeis: uma avaliação a partir de modelos uni e multivariados de previsão
}

Octávio Valente Campos ${ }^{\mathrm{a}}$;Wagner Moura Lamounier ${ }^{\mathrm{b}}$;Aureliano Angel Bressan ${ }^{\mathrm{c}}$

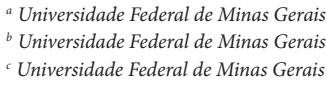

${ }^{b}$ Universidade Federal de Minas Gerais

' Universidade Federal de Minas Gerais

\section{Informações do Artigo}

Histórico do Artigo

Recebido: 26 de fevereiro de 2014

Aceito: 03 de maio de 2015

Palavras chave:

Retornos das ações

ARIMA

VAR

Índices Contábeis

\begin{abstract}
Resumo
O objetivo desta pesquisa foi comparar a rentabilidade de carteiras formadas a partir dos melhores modelos de previsão univariados e multivariados, identificando a relevância da informação contábil. Tal comparação foi feita por meio do uso de previsões com os modelos ARIMA (univariados) e os modelos VAR (multivariados). Os indicadores contábeis e os retornos das ações foram utilizados como dados de entrada para a geração das previsões e consequente formação de carteiras de investimentos - a série temporal de análise inicia-se em 30/03/1994, findando-se em 30/09/2011, com dados trimestrais. Dentro de uma amostra de 20 empresas, as carteiras de investimento foram composta pelas 5 empresas com maior rentabilidade prevista, comparando-se posteriormente as rentabilidades das carteiras formadas pelos modelos univariados contra as carteiras formadas pelos modelos multivariados. Os resultados apontaram, de forma geral, que as previsões baseadas em modelos multivariados tendem a fornecer aos investidores retornos superiores em investimentos de longo prazo (1 ano). Já os modelos univariados tendem a fornecer aos investidores retornos superiores em investimentos de custo prazo ( 1 trimestre). Assim, pode-se concluir que as informações contábeis em modelos de previsão apresentam maior relevância em estratégias de longo prazo.
\end{abstract}

Copyright @ 2015 FEA-RP/USP. Todos os direitos reservados

\section{INTRODUÇÃO}

O mercado de ações tem papel significante em várias economias do mundo, sendo umas das formas de captação de recursos pelas entidades. O financiamento com ações impulsiona o crescimento das empresas, fornecendo a elas melhores condições financeiras para a implementação de seus projetos de investimento, seja pelo baixo comprometimento de caixa proporcionado por esta modalidade, seja pela natureza permanente da captação (prazo indeterminado). Dada essa necessidade, diversos investidores buscam obter lucros ao comprar e vender ações. Para isto, é necessário conhecer o mercado, visando verificar qual o melhor momento para comprar ou vender esses ativos, ou seja, o investidor procura comprar a ação quando o preço dela está abaixo do que vale e vendê-la quando o preço está acima, obtendo desta forma o lucro. A dificuldade para tal transação é verificar quando o valor da ação estará em baixa e quando estará em alta. Neste contexto, um dos objetivos principais dos investidores para a referida análise é conseguir fazer previsões sobre os valores dos ativos de interesse.

Holden, Peel e Thompson (1990) argumentam que previsões são requeridas por duas razões básicas: (a) o futuro é incerto; (b) o impacto de muitas decisões tomadas no presente não é sentido no futuro, ou seja,

Autor Correspondente: Tel (31) 34097058

E-mail: octaviovc@yahoo.com.br (O. V.Campos); wagner@face.ufmg.br (W. M. Lamounier); aureliano@ufmg.br (A. A. Bressan)

Universidade Federal de Minas Gerais, Faculdade de Ciências Econômicas -Departamento de Ciências Contábeis - Av. Antônio Carlos, 6627 - FACE - Sala 2036

-Pampulha - 31270901 - Belo Horizonte, MG - Brasil 
apesar de haver atitudes que visam controlar o que acontecerá no futuro, ele ainda continua incerto. Neste cenário, Watts e Zimmerman (1986) argumentam que a importância da literatura sobre este tema se deve a necessidade do desenvolvimento de melhores modelos para a previsão do valor de títulos, principalmente ações. Foster (1986) corrobora com este argumento ao indicar que os analistas financeiros pertencem a um dos grupos interessados no comportamento das séries temporais financeiras, pois costumam apresentar em seus relatórios as previsões de lucros e dos valores das ações.

Para a previsão dos valores das ações os analistas financeiros recorrem frequentemente aos dados contábeis. Isso é evidenciado nas pesquisas em contabilidade financeira, que depois da mudança de paradigma derivada dos trabalhos de Ball e Brown (1968) e Beaver (1968), passaram a investigar corriqueiramente como e quando o mercado de ações reage às informações contábeis. De forma específica, de acordo com O’Hanlon, (1991), os analistas financeiros procuram saber se os dados contábeis concedem informações relevantes para tomarem suas decisões e, pontualmente, quais informações contábeis possuem maior utilidade para este fim.

Corriqueiramente, os interessados no histórico dos preços dos ativos utilizam ferramentas estatísticas com vistas a obter maior robustez em suas análises para as tomadas de decisões. Nesta ceara, há modelos econométricos que se utilizam apenas do histórico dos preços dos ativos para se fazer previsões (chamados de modelos univariados para séries temporais). Há modelos que utilizam também o histórico de outras variáveis que se relacionam com os preços dos ativos, como exemplo, os índices financeiros (chamados de modelos multivariados para séries temporais).

Neste sentido, verificam-se na literatura pesquisas como a de Oliveira, Montini e Bergmann (2008), cujo objetivo foi realizar previsões de retornos das ações utilizando modelos univariados, como os de redes neurais artificiais (RNA), e modelos do tipo Arima-Garch. Há trabalhos, como o de Van Doornik (2007), cujo objetivo foi desenvolver e testar empiricamente modelos multivariados, como os vetores auto-regressivos e os de correção de erros (VAR e VEC, respectivamente), baseados em variáveis contábeis e macroeconômicas para explicar o comportamento econômico-financeiro de uma empresa brasileira. Com isso, verifica-se que a literatura tem abordado tais temas, porém de forma separada, não fazendo uma comparação entre a capacidade preditiva dos modelos univariados e multivariados.

Portanto, é necessário analisar as relações entre os índices contábeis e os retornos das ações, verificandose se os dados contábeis fornecem informações relevantes para os usuários externos no momento de negociar um ativo. Assim, a presente pesquisa busca responder ao seguinte questionamento: A análise de indicadores contábeis amplia a capacidade de previsão dos retornos das ações?

Portanto, este estudo tem por objetivo comparar a rentabilidade de carteiras formadas a partir dos melhores modelos de previsão univariados (ARIMA) e multivariados (VAR), identificando a relevância da informação contábil. Esta pesquisa se mostra relevante tanto para o meio acadêmico quanto para os usuários do mercado de ações devido ao fornecimento de subsídios empíricos para a avaliação da rentabilidade de carteiras de ações por meio da comparação de estratégias de investimentos com o uso de índices contábeis.

\section{REFERENCIAL TEÓRICO \\ 2.1 RELEVÂNCIA DA INFORMAÇÃO CONTÁBIL}

A literatura contábil atribui o início da sua linha de investigação acerca da relevância da informação contábil ao trabalho seminal de Ball e Brown (1968), em que o foco é analisar a relação das variáveis contábeis e o mercado de capitais. Em seu estudo, os autores analisaram a relação entre o anúncio dos resultados das empresas e os preços das ações, verificando que as informações contábeis apresentam conteúdo informativo capaz de alterar as expectativas dos investidores, concluindo que os resultados contábeis possuem informações relevantes para o mercado de capitais.

O pronunciamento do CPC 00 (Estrutura Conceitual para a Elaboração e Apresentação das Demonstrações 
Contábeis) determina que para a informação contábil ser útil, ela precisa ser relevante, caracterizando a relevância como um aspecto qualitativo fundamental para as informações contábeis. Segundo este pronunciamento, uma informação relevante é aquela capaz de fazer diferença nas decisões que possam ser tomadas pelos usuários. A informação pode ser capaz de fazer diferença em uma decisão mesmo no caso de alguns usuários decidirem não a levar em consideração, ou se já tiverem tomado ciência de sua existência por outras fontes. A informação contábil-financeira é capaz de fazer diferença nas decisões se tiver valor preditivo, valor confirmatório ou ambos. Considerando-se outra abordagem, Barth et al. (2001) definem relevância como a associação entre informações contábeis e o valor de mercado da empresa, simplificando os conceitos apresentados pelo CPC 00.

Francis e Schipper (1999) consideram quatro possíveis interpretações e definições para a relevância contábil. A primeira está relacionada às pesquisas contábeis pela análise fundamentalista e seguem a premissa de que as informações contábeis antecipam os preços por capturar o valor intrínseco das ações. Essa abordagem pode ser aplicada em situações nas quais o mercado não reflete todas as informações disponíveis, sendo possível considerá-la em um mercado ineficiente. Neste contexto, o conceito de relevância da informação contábil é inferido a partir dos retornos obtidos por meio da implementação de estratégias baseadas em informações contábeis, partindo-se da premissa de que não são os preços de mercado que refletem o valor intrínseco da empresa, mas sim os números contábeis. Nesse caso, a informação contábil é considerada relevante se os portfólios formados com base em tais informações estiverem associados a retornos anormais. Araújo Júnior (2009) e Van Doornik (2007) são autores que alinham suas pesquisas a esta abordagem.

A segunda interpretação define que uma informação financeira possui relevância quando contém as variáveis utilizadas em um modelo de avaliação ou contribui para prever essas variáveis. Nessa abordagem, a informação contábil é considerada relevante quando pode ser utilizada para predizer resultados futuros, dividendos futuros ou fluxos de caixa futuro (FRANCIS e SCHIPPER, 1999). Este presente artigo se enquadra nesta interpretação.

A terceira abordagem prevê que a informação contábil será considerada relevante se for utilizada pelos investidores no processo de precificação. Neste sentido, a relevância é mensurada como sendo a habilidade das informações contábeis de alterar o conjunto de informações disponibilizadas no mercado, fazendo com que os investidores revisem suas expectativas e, por conseguinte, o preço. Essa abordagem caracteriza-se por estudos de curto intervalo de tempo, ou seja, analisa-se a reação do mercado de capitais em relação a uma informação contábil disponibilizada (por exemplo, anúncio dos resultados). Assim, a informação é considerada relevante quando sua divulgação altera as expectativas dos investidores acerca dos fluxos de caixa futuro da empresa e, por isso, causa uma mudança nos preços. Beaver et al. (1997) destacam que, nesse desenho de pesquisa, quando a informação contábil contém a capacidade de modificar as expectativas dos investidores pode-se considera-la com "conteúdo informacional" ao invés de "relevância". Os estudos realizados conforme essa abordagem tendem a seguir as metodologias propostas por Ball e Brown (1968).

A quarta interpretação de relevância contempla o papel das informações contábeis em resumir as transações da empresa, assim como outros eventos, em que a relevância é mensurada pela capacidade das informações contábeis capturarem ou resumirem informações, independentemente da fonte, que afetem os valores das ações.

Nessa perspectiva, de acordo com Francis e Schipper (1999) a contabilidade é vista como um instrumento para mensuração e não se pressupõe que os investidores estejam realmente utilizando as informações contábeis em suas decisões, ou que a informação contábil seja tempestiva.

O foco dessa abordagem está baseado na noção de que, se uma informação contábil (ou variável contábil) tem associação com os valores de mercado, então a informação contábil captura ou agrega informações que são utilizadas pelos participantes do mercado para determinar preços ou retornos. Barth et al. (2001) complementam que a informação contábil pode ser relevante - mas não relevante para as decisões dos investidores - mesmo se for substituída por informações mais tempestivas.

\subsection{Revisão da literatura internacional acerca do tema}


Com o objetivo de apresentar os estudos empíricos já realizados sobre o tema proposto, é apresentado quadros sintetizados para pormenorizar as informações. Segue, no Quadro 1 um resumo geral dos principais estudos internacionais que fundamentam a presente pesquisa.

Quadro 1. Estudos internacionais.

\begin{tabular}{|c|c|c|c|c|}
\hline AUTORIA & OBJETIVO GERAL & METODOLOGIA & AMOSTRA & PRINCIPAIS RESULTADOS \\
\hline $\begin{array}{l}\text { Bar-Yosef, } \\
\text { Callen e } \\
\text { Livnat (1987) }\end{array}$ & $\begin{array}{l}\text { Testar empiricamente as } \\
\text { relações entre o lucro e } \\
\text { o investimento das } \\
\text { empresas. }\end{array}$ & $\begin{array}{c}\text { Teste de Causalidade } \\
\text { Granger }\end{array}$ & $\begin{array}{l}644 \text { empresas } \\
\text { industriais - } \\
\text { EUA. } \\
\text { Dados anuais de } \\
1960 \text { a } 1981 .\end{array}$ & $\begin{array}{l}\text { Modelos bivariados foram } \\
\text { superiores aos modelos univariados } \\
\text { para prever os investimentos } \\
\text { futuros, mas não na previsão de } \\
\text { lucros futuros. }\end{array}$ \\
\hline $\begin{array}{l}\text { O’Hanlon } \\
\text { (1991) }\end{array}$ & $\begin{array}{l}\text { Verificar se os retornos } \\
\text { contábeis teriam } \\
\text { impactos nos retornos } \\
\text { das ações, ou vice-versa. }\end{array}$ & $\begin{array}{c}\text { Teste de Causalidade } \\
\text { Granger }\end{array}$ & $\begin{array}{l}222 \text { empresas } \\
\text { do Reino Unido. } \\
\text { Dados anuais de } \\
1968 \text { a } 1987\end{array}$ & $\begin{array}{l}\text { Há causalidade bidirecional entre as } \\
\text { variáveis. O retorno contábil exerce } \\
\text { mais influencia sobre o retorno das } \\
\text { ações do que o contrário. }\end{array}$ \\
\hline $\begin{array}{l}\text { Martikainen } \\
\text { e Puttonen } \\
\quad(1993)\end{array}$ & $\begin{array}{l}\text { Investigar a eficiência } \\
\text { informacional dos } \\
\text { mercados de ações } \\
\text { focando na relação entre } \\
\text { os preços das ações, os } \\
\text { retornos contábeis e } \\
\text { os fluxos de caixa das } \\
\text { empresas. }\end{array}$ & $\begin{array}{l}\text { Análise de co- } \\
\text { integração }\end{array}$ & $\begin{array}{l}21 \text { empresas } \\
\text { da Finlândia. } \\
\text { Dados anuais de } \\
1974 \text { a } 1989\end{array}$ & $\begin{array}{l}\text { Os retornos das ações causam os } \\
\text { retornos contábeis e não o contrário. } \\
\text { Esse resultado foi diferente do } \\
\text { apresentado por O’Hanlon (1991) }\end{array}$ \\
\hline $\begin{array}{l}\text { Jindrichovska } \\
\text { (2001) }\end{array}$ & $\begin{array}{l}\text { Investigar a relação entre } \\
\text { os dados contábeis e } \\
\text { o retorno do preço de } \\
\text { mercado das ações das } \\
\text { empresas listadas na } \\
\text { Bolsa de Valores de Praga } \\
\text { (PSE) }\end{array}$ & $\begin{array}{l}\text { Análise de co- } \\
\text { integração }\end{array}$ & $\begin{array}{l}63 \text { empresas } \\
\text { industriais } \\
\text { da República } \\
\text { Tcheca. Dados } \\
\text { de } 1993 \text { a } 1998 .\end{array}$ & $\begin{array}{l}\text { Verificou-se a existência de relação } \\
\text { entre as variáveis estudadas para } \\
\text { medições de um ano ou mais. }\end{array}$ \\
\hline $\begin{array}{l}\text { Mahmood e } \\
\text { Fatah (2007) }\end{array}$ & $\begin{array}{l}\text { Examinar o poder } \\
\text { preditivo, de curto } \\
\text { e longo prazo, entre } \\
\text { o retorno das ações, } \\
\text { rendimento dos } \\
\text { dividendos e rendimento } \\
\text { dos lucros. }\end{array}$ & $\begin{array}{l}\text { Análise de co- } \\
\text { integração }\end{array}$ & $\begin{array}{l}\text { Empresas da } \\
\text { Malásia. Dados } \\
\text { mensais de } 1989 \\
\text { a } 2005 .\end{array}$ & $\begin{array}{l}\text { Verificou-se que todas as variáveis } \\
\text { investigadas possuem poder de } \\
\text { previsão umas das outras. }\end{array}$ \\
\hline $\begin{array}{l}\text { Alexander, } \\
\text { Falta e Willett } \\
\qquad(2012)\end{array}$ & $\begin{array}{c}\text { Verificar a relevância das } \\
\text { informações contábeis na } \\
\text { previsão dos retornos de } \\
\text { mercado }\end{array}$ & $\begin{array}{l}\text { Análise de co- } \\
\text { integração e } \\
\text { regressões }\end{array}$ & $\begin{array}{c}\text { A empresa } \\
\text { norte-americana } \\
\text { Abbott } \\
\text { Laboratories } \\
\text { Inc. Dados de } \\
\text { 1959 a } 2008\end{array}$ & $\begin{array}{c}\text { A variável mais co-integrada com } \\
\text { os retornos das ações foi o Lucro } \\
\text { Líquido, principalmente no longo } \\
\text { prazo. }\end{array}$ \\
\hline Tswei (2013) & $\begin{array}{l}\text { Avaliar a relação entre } \\
\text { os dados contábeis e } \\
\text { o retorno no preço de } \\
\text { mercado das ações }\end{array}$ & $\begin{array}{l}\text { Vetor de correção de } \\
\quad \text { erros (VEC) }\end{array}$ & $\begin{array}{l}\text { Empresas de } \\
\text { Taiwan. Dados } \\
\text { trimestrais de } \\
1981 \text { a } 2012\end{array}$ & $\begin{array}{l}\text { Observou-se baixa relevância nas } \\
\text { análises de longo prazo em contraste } \\
\text { com maior relevância no curto } \\
\text { prazo. }\end{array}$ \\
\hline
\end{tabular}

Fonte: elaboração própria. 
2.3 Revisão da literatura nacional sobre o tema.

No Quadro 2 é resumido as principais pesquisas nacionais que fundamentam o presente estudo.

Quadro 2. Estudos nacionais.

\begin{tabular}{|c|c|c|c|c|}
\hline AUTORIA & $\begin{array}{l}\text { OBJETIVO } \\
\text { GERAL }\end{array}$ & METODOLOGIA & AMOSTRA & $\begin{array}{l}\text { PRINCIPAIS } \\
\text { RESULTADOS }\end{array}$ \\
\hline $\begin{array}{l}\text { Van Doornik } \\
\quad(2007)\end{array}$ & $\begin{array}{l}\text { Verificar o relacionamento } \\
\text { entre variáveis contábeis e } \\
\text { macroeconômicas que preveja } \\
\text { o comportamento econômico- } \\
\text { financeiro de uma empresa } \\
\text { brasileira. }\end{array}$ & $\begin{array}{c}\text { Vetores Auto- } \\
\text { Regressivos (VAR) }\end{array}$ & $\begin{array}{c}\text { Estudo da } \\
\text { PETROBRÁS - } \\
\text { Petróleo Brasileiro } \\
\text { S/A }\end{array}$ & $\begin{array}{l}\text { Verificou-se que Vetores } \\
\text { Auto-Regressivos } \\
\text { possuem maior } \\
\text { capacidade preditiva } \\
\text { do que o sistema de } \\
\text { equações múltiplas. }\end{array}$ \\
\hline $\begin{array}{l}\text { Costa Jr, } \\
\text { Meurer e } \\
\text { Cupertino } \\
(2007)\end{array}$ & $\begin{array}{c}\text { Verificar o relacionamento entre } \\
\text { as séries dos retornos contábeis } \\
\text { (ROE) e dos retornos de } \\
\text { mercado das ações (RET). }\end{array}$ & $\begin{array}{l}\text { Causalidade de } \\
\text { Granger }\end{array}$ & $\begin{array}{l}97 \text { empresas da } \\
\text { BM\&FBovespa. } \\
\text { Dados trimestrais } \\
\text { de } 1995 \text { a } 2007 .\end{array}$ & $\begin{array}{c}\text { Há causalidade } \\
\text { bidirecional entre as } \\
\text { variáveis. O retorno } \\
\text { contábil exerce maior } \\
\text { influencia sobre o } \\
\text { retorno das ações do que } \\
\text { o contrário. Resultado } \\
\text { similar ao apresentado } \\
\text { por O’Hanlon (1991). }\end{array}$ \\
\hline $\begin{array}{l}\text { Oliveira, } \\
\text { Montini e } \\
\text { Bergmann } \\
\quad(2008)\end{array}$ & $\begin{array}{l}\text { Realizar previsões de séries de } \\
\text { retornos de ações de empresas } \\
\text { dos setores financeiro, de } \\
\text { alimentos, industrial e de } \\
\text { serviços. }\end{array}$ & $\begin{array}{l}\text { Redes neurais } \\
\text { artificiais (RNA) } \\
\text { e modelos Arima- } \\
\text { Garch. Modelos } \\
\text { unicamente } \\
\text { univariados. }\end{array}$ & $\begin{array}{c}8 \text { empresas da } \\
\text { BM\&FBovespa, } \\
\text { duas de cada setor. }\end{array}$ & $\begin{array}{l}\text { Verificou-se que as } \\
\text { previsões realizadas } \\
\text { pelas duas técnicas } \\
\text { têm desempenhos } \\
\text { parecidos, não revelando } \\
\text { superioridade de } \\
\text { nenhuma técnica. }\end{array}$ \\
\hline $\begin{array}{l}\text { Galdi e Lopes } \\
\qquad(2008)\end{array}$ & $\begin{array}{l}\text { Analisar a relação entre o lucro } \\
\text { contábil e o preço das ações }\end{array}$ & $\begin{array}{l}\text { Análise de co- } \\
\text { integração }\end{array}$ & $\begin{array}{l}41 \text { empresas da } \\
\text { América Latina. }\end{array}$ & $\begin{array}{l}\text { Evidenciou-se que existe } \\
\text { um relacionamento } \\
\text { de longo prazo entre o } \\
\text { lucro e os preços das } \\
\text { ações para a maior parte } \\
\text { das empresas analisadas }\end{array}$ \\
\hline $\begin{array}{l}\text { Sonza e } \\
\text { Kloeckner } \\
(2009)\end{array}$ & $\begin{array}{l}\text { Verificar o relacionamento, de } \\
\text { curto e longo prazo, entre o } \\
\text { lucro contábil e o respectivo } \\
\text { preço das ações. }\end{array}$ & $\begin{array}{c}\text { Análise de co- } \\
\text { integração e do Vetor } \\
\text { de Correção de Erros } \\
\text { (VEC). }\end{array}$ & $\begin{array}{l}20 \text { empresas da } \\
\text { BM\&FBovespa. } \\
\text { Dados trimestrais } \\
\text { de } 1990 \text { a } 2008 .\end{array}$ & $\begin{array}{l}\text { Verificou-se que os } \\
\text { lucros influenciam o } \\
\text { preço das ações no longo } \\
\text { prazo. Esse resultado é } \\
\text { divergente em alguns } \\
\text { pontos ao apresentado } \\
\text { por Costa Jr, Meurer e } \\
\text { Cupertino (2007). }\end{array}$ \\
\hline $\begin{array}{l}\text { Brugni et al. } \\
\quad(2015)\end{array}$ & $\begin{array}{l}\text { Investigar se existem incentivos } \\
\text { para a informação contábil } \\
\text { divulgada seguir o preço das } \\
\text { ações e não o contrário }\end{array}$ & $\begin{array}{l}\text { Causalidade de } \\
\text { Granger e regressão } \\
\text { logística. }\end{array}$ & $\begin{array}{l}20 \text { empresas da } \\
\text { BM\&FBovespa. }\end{array}$ & $\begin{array}{c}\text { Observou-se para } \\
\text { metade da amostra o } \\
\text { componente surpresa do } \\
\text { lucro Granger-causando } \\
\text { preço e pra outra metade } \\
\text { o mercado conseguindo } \\
\text { antecipar, no curto } \\
\text { prazo, o componente } \\
\text { surpresa do lucro futuro. }\end{array}$ \\
\hline
\end{tabular}

Fonte: elaboração própria. 


\section{HIPÓTESES}

Conforme apontado pela literatura apresentada, os indicadores contábeis possuem poder de previsão sobre o retorno das ações, portanto, a hipótese desta pesquisa é:

$H_{0}$ : Os modelos multivariados fornecem melhores previsões sobre os retornos das ações do que os modelos univariados, o que indicaria a relevância da informação contábil para previsões de retornos das ações.

\section{METODOLOGIA}

\subsection{Amostra}

A amostra foi composta por todas as empresas de capital aberto que fazem parte do Índice Bovespa (Ibovespa) e que apresentaram todas as observações trimestrais consecutivas das variáveis em estudo. Os dados foram coletados no Economática ${ }^{\circledR}$ e no site da BM\&FBOVESPA. Desta forma, a amostra ficou composta por 20 empresas, conforme apresentado na TABELA 1.

O espaço temporal mínimo se justifica porque para uma eficaz modelagem de séries temporais é necessário uma longa série de observações, evitando-se assim, problemas relacionados à micro-numerosidade. $\mathrm{O}$ valor estipulado normalmente pela literatura como mínimo é 50 observações. Deste valor é desconsiderando os dados que serão utilizados posteriormente para a comparação das previsões.

Tabela 1. Amostra.

\begin{tabular}{cccc}
\hline \hline Nome de pregão & Classe & Setor & Série temporal \\
\hline \hline Ambev & PN & Cervejas e refrigerantes & $30 / 03 / 1994$ à 30/09/2011 \\
Brasil Telec & PN & Telecomunicações & $30 / 03 / 1994$ à 30/09/2011 \\
Braskem & PNA & Química & $30 / 03 / 1994$ à 30/09/2011 \\
Cemig & PN & Energia Elétrica & $30 / 03 / 1994$ à 30/09/2011 \\
Eletrobras & PNB & Energia Elétrica & $30 / 03 / 1994$ à 30/09/2011 \\
Gerdau & PN & Siderur \& Metalur & $30 / 03 / 1994$ à 30/09/2011 \\
Gerdau Met & PN & Siderur \& Metalur & $30 / 03 / 1994$ à 30/09/2011 \\
Klabin S/A & PN & Papel e Celulose & $30 / 03 / 1994$ à 30/09/2011 \\
Light S/A & ON & Energia Elétrica & $30 / 03 / 1994$ à 30/09/2011 \\
Lojas Americ & PN & Produtos diversos & $30 / 03 / 1994$ à 30/09/2011 \\
Marcopolo & PN & Material de Transporte & $30 / 03 / 1994$ à 30/09/2011 \\
P.Acucar-Cbd & PN & Alimentos & $30 / 03 / 1996$ à 30/09/2011 \\
Petrobras & PN & Petróleo. Gás e Energia & $30 / 03 / 1994$ à 30/09/2011 \\
Randon Part & PN & Material de Transporte & $30 / 03 / 1994$ à 30/09/2011 \\
Sid Nacional & ON & Siderur \& Metalur & $30 / 03 / 1994$ à 30/09/2011 \\
Souza Cruz & ON & Cigarros e Fumo & $30 / 03 / 1994$ à 30/09/2011 \\
Suzano Papel & PNA & Papel e Celulose & $30 / 03 / 1994$ à 30/09/2011 \\
Telef Brasil & PN & Telecomunicações & $30 / 03 / 1994$ à 30/09/2011 \\
Usiminas & PNA & Siderur \& Metalur & $30 / 03 / 1994$ à 30/09/2011 \\
Vale & PNA & Minerais Metálicos & $30 / 03 / 1994$ à 30/09/2011 \\
\hline \hline
\end{tabular}

Fonte: Elaborada pelos autores

Conforme mostrado na TABELA 1, somente a P.Acucar-Cbd teve sua série iniciada em 30/03/1996. Em todas as demais empresas as séries começam em 30/03/1994, findando-se em 30/09/2011. A classe de ações escolhida para cada empresa foi a que apresentou maior liquidez. 


\subsection{Variáveis contábeis}

Dentre os índices pesquisados de liquidez, estrutura de capital e rentabilidade serão apresentados apenas os que possuíram poder preditivo em relação aos retornos das ações (esta é a variável que se busca prever). Para ponderar quaisquer desvios no retorno das ações, foi utilizada no cálculo desta variável a cotação trimestral média do preço das ações ajustadas de acordo com os dividendos propostos.

A principal variável em estudo é o retorno do mercado das ações (RETit) por ser a variável cujo comportamento se busca prever. Esta variável foi utilizada tanto nos modelos ARIMA como nos modelos VAR. Nos trabalhos que compõe a revisão de literatura desta presente pesquisa, predomina-se como variáveis de análise o RETit e o retorno do Patrimônio Líquido (ROEit). Já as demais variáveis inseridas nos modelos, conforme Quadro 3, são justificadas pela busca exploratória de outros indicadores com poder preditivo.

Quadro 3. Variáveis analisadas.

\begin{tabular}{|c|c|c|c|}
\hline Indicadores & Fórmula & Em que: & Utilizada \\
\hline $\begin{array}{l}\text { Retorno de mercado } \\
\text { das ações - RET }\end{array}$ & $R E T_{i t}=\frac{P_{i t} \mathbf{I} P_{i t-\mathbf{1}}}{P_{i t-\mathbf{1}}}$ & $\begin{array}{c}\text { Pit é o preço médio trimestral da } \\
\text { ação mais líquida da empresa } i \text { no } \\
\text { trimestre } t .\end{array}$ & $\begin{array}{l}\text { Modelos } \\
\text { univariados e } \\
\text { multivariados. } \\
20 \text { empresas. }\end{array}$ \\
\hline $\begin{array}{l}\text { Retorno do Patrimônio } \\
\text { Líquido- ROE }\end{array}$ & 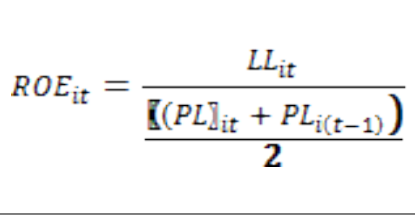 & $\begin{array}{l}L L_{i t} \text { é o lucro líquido da empresa } i \\
\text { no trimestre } t \text {; } \\
P L_{i t} \text { é o patrimônio líquido da } \\
\text { empresa } i \text { no trimestre } t \text {. }\end{array}$ & $\begin{array}{l}\text { Modelos } \\
\text { multivariados. } \\
5 \text { empresas. }\end{array}$ \\
\hline Giro do Ativo - GA & $G A_{i t}=\frac{V L_{i t}}{A T_{i t}}$ & $\begin{array}{l}V L_{i t} \text { representa as vendas líquidas } \\
\text { da empresa } i \text { no trimestre } t \text {; e } \\
A T_{i t} \text { é o ativo total da empresa } i \text { no } \\
\text { trimestre } t \text {. }\end{array}$ & $\begin{array}{l}\text { Modelos } \\
\text { multivariados. } \\
3 \text { empresas. }\end{array}$ \\
\hline Margem Líquida - ML & $M L_{i t}=\frac{L L_{i t}}{V L_{i t}}$ & $\begin{array}{l}L L_{i t} \text { é o lucro líquido da empresa } i \\
\text { no trimestre } t \text {; } \\
V L_{i t} \text { representa as vendas líquidas } \\
\text { da empresa } i \text { no trimestre } t \text {. }\end{array}$ & $\begin{array}{l}\text { Modelos } \\
\text { multivariados } \\
6 \text { empresas. }\end{array}$ \\
\hline Liquidez Corrente - LC & $L C_{i t}=\frac{A C_{i t}}{P C_{i t}}$ & $\begin{array}{l}A C_{i t} \text { é o ativo circulante da empresa } \\
i \text { no trimestre } t \text {; } \\
P C_{i t} \text { é o passivo circulante da } \\
\text { empresa } i \text { no trimestre } t \text {. }\end{array}$ & $\begin{array}{l}\text { Modelos } \\
\text { multivariados } \\
1 \text { empresa. }\end{array}$ \\
\hline $\begin{array}{c}\text { Composição do } \\
\text { Endividamento - CE }\end{array}$ & $C E_{i t}=\frac{P C_{i t}}{C T_{i t}}$ & $\begin{array}{l}P C_{i t} \text { é o passivo circulante da } \\
\text { empresa } i \text { no trimestre } t \text {; e } \\
C T_{i t} \text { é o capital de terceiros da } \\
\text { empresa } i \text { no trimestre } t \text {. }\end{array}$ & $\begin{array}{c}\text { Modelos } \\
\text { multivariados } \\
3 \text { empresas. }\end{array}$ \\
\hline
\end{tabular}

Fonte: Elaborada pelos autores

Para a análise e discussão sobre séries temporais é necessário abordar a estacionariedade dessas séries. Neste estudo, foi verificada a estacionaridade destas variáveis por meio dos testes de raiz unitária denominados Dickey-Fuller Aumentado (ADF) e Phillips-Perron (PP) - (PHILLIPS e PERRON, 1988).

\subsection{Modelos Univariados - Modelos ARIMA.}

De acordo com Pindyck e Rubinfeld (2004) e Gujarati (2006), o modelo auto-regressivo (AR) é composto pela soma ponderada dos valores passados da variável dependente além do termo de perturbação aleatória. Já o 
modelo de médias móveis (MA) é delineado pela soma ponderada de perturbações aleatórias correntes e defasadas. Como em muitos casos os processos possuem características de ambos os tipos de modelos, podem ser assim formalizado: $y_{t}=\phi_{1} y_{t-1}+\cdots+\phi_{p} y_{t-p}+\beta_{0}+\varepsilon_{t}-\theta_{1} \varepsilon_{t-1}-\cdots-\theta_{q} \varepsilon_{t-q}$. Assim, este modelo utilizase apenas da série temporal da variável retorno das ações para realizar as previsões. Portanto, neste modelo será utilizado apenas a variável retorno da ação.

Para encontrar os melhores parâmetros foi seguida a metodologia de Box-Jenkins em que são analisas a função de autocorrelação (FAC) e a função de autocorrelação parcial (FACP), conforme o Quadro 1.

Quadro 4. Padrões teóricos típicos das funções de Autocorrelação.

\begin{tabular}{|c|c|c|}
\hline Modelo & FAC & FACP \\
\hline AR $(p)$ & Queda exponencial. & Picos significativos nos “p” lags do modelo. \\
\hline MA $(q)$ & Picos significativos nos “q” lags do modelo. & Queda exponencial. \\
\hline ARMA $(p, q)$ & Queda exponencial se $k>q$ & Queda exponencial se $k>p$ \\
\hline
\end{tabular}

Fonte: Adaptado de Lamounier (2001, p. 71).

Para auxiliar na escolha da ordem foi utilizado como critério o AIC (Akaike Information Criterion). Já para a validação dos modelos foi utilizados os testes de Jarque-Bera a fim de observar a normalidade e o teste de Breusch-Godfrey para verificar a autocorrelação dos resíduso.

\subsection{Modelos Multivariados - Vetores Auto-Regressivos (VAR)}

De acordo com Enders (2003), o modelo VAR, em sua forma reduzida, é formalizado por $X_{t}=A^{-1} B_{0}+\sum_{i=1}^{p} A^{-1} B_{i} X_{t-1}+A^{-1} B \varepsilon_{t}$, em que: $\Phi_{0}=A^{-1} B_{i} ; \mathrm{i}=0,1, \ldots, \mathrm{p} ; \mathrm{e} \boldsymbol{B} \varepsilon_{\boldsymbol{t}}=\boldsymbol{A} \boldsymbol{e}_{\boldsymbol{t}}$ assumindo como hipótese que os parâmetros sejam estacionários e os erros se comportem como um ruído branco. Assim, como os modelos são compostos por vetores auto-regressivos, tanto o retorno das ações como os índices contábeis se comportam como variáveis dependentes e independentes no modelo.

Para auxiliar na escolha da ordem foi utilizado como critério o AIC (Akaike Information Criterion) adaptado aos modelos multivariados. Para a validação dos modelos foram utilizados os testes de Jarque-Bera a fim de observar a normalidade e o teste de Ljung-Box para verificar a autocorrelação dos resíduos.

$\mathrm{Na}$ busca da identificação dos índices que fornecem poder de previsão dos retornos das ações e em qual defasagem há esse poder de previsão, foi utilizado o teste de causalidade de Granger - (GRANGER, 1969). Segundo Pindycke Rubinfeld(2004), o teste é formalizado por: $X_{t}=\sum_{i=1}^{n} a_{i} Y_{t-i}+\sum_{i=1}^{n} b_{j} X_{t-j}+\epsilon t$ e $Y_{t}=\sum_{i=1}^{n} c_{i} X_{t}-1+\sum_{j=1}^{n} d_{j} Y_{t-j}+\varphi_{t}$, , em que a hipótese nula é $H_{\mathbf{0} x}: \Sigma_{a i}=\mathbf{0}$ para a primeira equação e $H_{\mathbf{0} y}: \Sigma_{c i}=\mathbf{0}$ para a segunda.

\subsection{Modelos Univariados vs. Modelos Multivariados}

Para evitar que os resultados analisados apresentem problemas relacionados a data-snooping (resultados encontrados devido ao acaso) foram separados os últimos três anos (quatro observações trimestrais por ano) para a comparação entre as carteiras de investimento. Assim, as carteiras são comparadas em três momentos distintos: $1^{\mathrm{o}}$ momento - $12 / 08$ à 09/09; $2^{\circ}$ momento - 12/09 à 09/10; e $3^{\circ}$ momento - 12/10 à 09/11. Esta análise em vários momentos evita que os resultados ocorram simplesmente devido ao acaso e não devido a uma capacidade preditiva superior de algum modelo de previsão utilizado.

Para observar o comportamento das previsões em curto e longo prazo, dentro de cada momento de análise, foram montados seis portfólios (três baseados nos modelos univariados e três baseados nos modelos multivariados) de acordo com os retornos previstos em três períodos de tempo: $1^{\circ}$ trimestre; $1^{\circ}$ semestre; e 1 ano. Assim, de acordo com as previsões realizadas para o $1^{\circ}$ trimestre, foram compostos dois portfólios: um baseado nas previsões dos modelos univariados e o outro baseado nas previsões dos modelos multivariados. Da mesma forma, foi feita a elaboração dos portfólios baseados nos retornos previstos para um semestre e para um ano.

De acordo com as previsões realizadas foram formadas carteiras de investimento com as cinco ações 
que alcançaram as maiores rentabilidades previstas - cada ação com a mesma proporcionalidade de investimento das demais (20\%). Segundo Brito e Brito (2002), este quantitativo de ações em uma carteira já captura uma parcela expressiva dos possíveis ganhos de diversificação no cenário brasileiro. Desta forma, as cinco empresas que apresentaram os maiores retornos previstos foram as escolhidas para compor cada portfólio. Na análise dos períodos seguintes o mesmo procedimento foi utilizado independente do resultado anterior.

Para que houvesse proporcionalidade no total investido em cada empresa, optou-se por utilizar, na composição de cada portfólio, o mesmo volume de investimento em cada ação, ou seja, o portfólio inicial é composto por 5 ações, cada uma com $20 \%$ do total investido. Este procedimento se faz necessário para se identificar de forma mais objetiva e balanceada o retorno do portfólio como um todo, impedindo-se que a ação de apenas uma empresa exerça influência positiva ou negativa no retorno total da carteira. Portanto, para se chegar ao retorno total da carteira, foi calculada a média simples dos retornos acumulados das empresas.

Os custos das operações de compra e venda de ações não foram considerados, já que para cada carteira analisada há apenas duas transações: compra das ações na composição do portfólio e venda das ações ao fim de cada projeção temporal. Assim, este custo de negociação não possui significância dentro das rentabilidades obtidas.

Em outra análise, considerando o risco dos investimentos, foi utilizado o Índice de Sharpe (IS). Esta medida expressa a relação entre retorno e risco, informando se o investimento oferece rentabilidade compatível com o risco a que expõe o investidor. Este índice, de acordo com Bodie, Kane e Marcus (2002), é assim representado: , em que $\bar{R}_{p, t}$ é o retorno da carteira no período t; $R_{F, t}$ é o retorno do ativo livre de risco no período $\mathrm{t}$ [no caso foi utilizado o CDI (Certificados de Depósitos Interbancários)]; e ${ }^{\sigma}$,t é o Desvio padrão do portfólio. Desse modo, o Índice de Sharpe mede o retorno adicional que a carteira obteve sobre um ativo livre de risco,

\section{RESULTADOS}

\subsection{Especificação dos modelos.}

Tabela 2. Especificações dos modelos Univariados.

\begin{tabular}{c|c|c|c}
\hline Empresas & ARIMA & Empresas & ARIMA \\
\hline Ambev & $(1.0 .0)^{\star}$ & Marcopolo & $(0.0 .1)$ \\
\hline Brasil Telec & $(0.0 .1)^{\star}$ & P.Acucar-Cbd & $(1.0 .1)$ \\
\hline Braskem & $(1.0 .0)^{\star}$ & Petrobras & $(2.0 .0)^{\star}$ \\
\hline Cemig & $(0.0 .1)^{\star}$ & Randon Part & $(0.0 .1)$ \\
\hline Eletrobras & $(0.0 .1)^{\star}$ & Sid Nacional & $(0.0 .1)$ \\
\hline Gerdau & $(0.0 .1)$ & Souza Cruz & $(1.0 .0)^{\star}$ \\
\hline Gerdau Met & $(0.0 .1)$ & Suzano Papel & $(0.0 .1)^{\star}$ \\
\hline Klabin S/A & $(0.0 .2)^{\star}$ & Telef Brasil & $(1.0 .0)^{\star}$ \\
\hline Light S/A & $(0.0 .1)^{\star}$ & Usiminas & $(0.0 .1)$ \\
\hline Lojas Americ & $(0.0 .1)^{\star}$ & Vale & \\
\hline
\end{tabular}

*modelos sem intercepto.

Fonte: Resultados da pesquisa.

Nas estimação univariada, em todas as empresas foi possível especificar algum modelo de previsão, isto é, nenhuma série verificada apresentou um típico comportamento de ruído branco (white noise), cuja previsibilidade seria afetada.

A predominância de modelos que apresentaram os menores valores para o critério de informação de Akaike foram ARIMA (0.0.1) (com ou sem intercepto) - com 13 ocorrências - e ARIMA (1.0.0) (com ou sem intercepto) - com 5 ocorrências. Isto evidencia que para estas séries de retornos de ações, as primeiras defasagens, tanto na parte auto regressiva (AR) como principalmente na parte de Médias Moveis (MA), são as que fornecem maior poder de previsão. Os outros tipos de modelos verificados foram: ARIMA (0.0.2)* e ARIMA (2.0.0)*. 
Tabela 3. Especificações dos modelos Multivariados.

\begin{tabular}{|c|c|c|}
\hline Empresas & Indicador & VAR estimado \\
\hline Ambev & $\mathrm{ROE}$ & $(6 / 6)^{*}$ \\
\hline Brasil Telec & - & - \\
\hline Braskem & ML & $(3 / 4)$ \\
\hline Cemig & ROE & $(5 / 5)^{*}$ \\
\hline Eletrobrás & $\mathrm{CE}$ & $(1 / 1)$ \\
\hline Gerdau & ML & $(4 / 4)^{*}$ \\
\hline Gerdau Met & ML & $(3 / 4)$ \\
\hline Klabin S/A & $\mathrm{CE}$ & $(3 / 3)^{*}$ \\
\hline Light S/A & GA & $(1 / 2)^{*}$ \\
\hline Lojas Americ & GA & $(2 / 3)^{*}$ \\
\hline Marcopolo & $\mathrm{CE}$ & $(5 / 5)$ \\
\hline P.Acucar-Cbd & ML & $(1 / 3)^{*}$ \\
\hline Petrobrás & ML & $(3 / 3)^{*}$ \\
\hline Randon Part & GA & $(2 / 3)^{*}$ \\
\hline Sid Nacional & ROE & $(2 / 2)$ \\
\hline Souza Cruz & $\mathrm{ROE}$ & $(1 / 1)$ \\
\hline Suzano Papel & - & - \\
\hline Telef Brasil & $\mathrm{LC}$ & $(5 / 5)$ \\
\hline Usiminas & $\mathrm{ROE}$ & $(1 / 2)^{*}$ \\
\hline Vale & ML & $(3 / 3)^{*}$ \\
\hline
\end{tabular}

*modelos sem intercepto.

Fonte: Resultados da pesquisa.

Para as empresas Brasil Telec e Suzano Papel não foi possível especificar um modelo VAR com os índices contábeis apresentando parâmetros significativos. Nenhum indicador contábil analisado apresentou causalidade de Granger com os retornos das ações da empresa Suzano Papel. Já para a empresa Brasil Telec a LC apresentou causalidade com RET, porém, nas especificações dos modelos VAR, nenhum parâmetro se apresentou significativo estatisticamente ao nível de $5 \%$.

Em algumas empresas, mais de um índice apresentou causalidade de Granger com os retornos das ações; no entanto, na estimação dos modelos não foi possível encontrar parâmetros significativos quando eles eram usados simultaneamente como variáveis independentes nos modelos VAR. Desta forma, só foi possível encontrar parâmetros significativos quando foi utilizado um dos indicadores, isoladamente, para prever o RET.

Conforme verificado na tabela 3 e de acordo com o critério de informação de Akaike, a Margem Líquida (ML) foi o indicador que apresentou o maior número de casos (6 empresas) com significância estatística para prever o RET, seguido pelo ROE (5 empresas), GA (3 empresas), CE (3 empresas) e LC (1 empresa). O único índice que não se apresentou como o melhor pra prever o RET em alguma das empresas foi a PCT. Alguns índices foram significantes apenas nas primeiras defasagens (Eletrobrás: VAR (1/1) entre RET e CE) e outros apenas nas ultimas defasagens (Ambev: VAR (6/6) entre RET e ROE). Isso demonstra que para algumas empresas as relações entre os índices e os retornos das ações se dão no curto prazo e para outras no longo prazo.

Apesar da presença de causalidade bidirecional encontrada pelo teste de Granger, nas estimações dos modelos, houve significância estatística dos retornos das ações (RET) como variável explicativa apenas pra as empresas Cemig e Marcopolo. Isso pode ser explicado pelo fato da causalidade no sentido dos retornos para os índices ocorrem em maiores defasagens, enquanto os melhores modelos especificados apresentaram predominância em menores defasagens 


\subsection{Comparação das carteiras.}

Tabela 4. Comparação das carteiras.

\begin{tabular}{|c|c|c|c|}
\hline $1^{\circ}$ momento de análise & $1^{\circ}$ trimestre & $1^{\circ}$ semestre & 1 ano \\
\hline Retorno real - Modelos Univariados & $-15,5688 \%$ & $-23,9098 \%$ & $-0,7133 \%$ \\
\hline Retorno real - Modelos Multivariados & $-44,0764 \%$ & $-41,2090 \%$ & $-12,2778 \%$ \\
\hline $2^{\circ}$ momento de análise & $1^{\circ}$ trimestre & $1^{\circ}$ semestre & 1 ano \\
\hline Retorno real - Modelos Univariados & $20,1419 \%$ & $24,7309 \%$ & $26,1417 \%$ \\
\hline Retorno real - Modelos Multivariados & $22,3362 \%$ & $29,9144 \%$ & $51,4103 \%$ \\
\hline $3^{\circ}$ momento de análise & $1^{\circ}$ trimestre & $1^{\circ}$ semestre & 1 ano \\
\hline Retorno real - Modelos Univariados & $17,6639 \%$ & $16,2825 \%$ & $-5,7292 \%$ \\
\hline Retorno real - Modelos Multivariados & $14,4378 \%$ & $6,0785 \%$ & $12,7374 \%$ \\
\hline
\end{tabular}

Fonte: Resultados da pesquisa.

De acordo com o primeiro momento de análise, um investimento realizado com base em ambos os modelos de previsão resultaria em prejuízos significantes, seja no trimestre, no semestre ou no ano. Verificouse também que os modelos univariados foram superiores aos modelos multivariados (apresentaram menores prejuízos). Como forma de comparação, apenas no $1^{\circ}$ trimestre de previsão, a rentabilidade da carteira Univariada obteve menor prejuízo que uma carteira de mercado (Ibovespa), em que neste período apresentou a rentabilidade de $-25,64 \%$. Nesse momento de análise houve uma crise econômica mundial, o que compromete o mercado de capitais, podendo ter causado a ineficiência dos modelos de previsão. Portanto, neste período, uma opção seria investir em ativos livre de risco.

Já no segundo momento de análise, observou-se que os modelos multivariados de previsão foram superiores aos modelos univariados; no trimestre, no semestre e no ano. No mesmo período, ambos os modelos de previsão apresentaram rentabilidades superiores ao retorno da carteira de mercado (Ibovespa), em que esta obteve: $15,38 \%$ no trimestre; $16,86 \%$ no semestre; e $14,56 \%$ no ano. Desta forma, considerando o segundo momento de análise, o mais indicado seria utilizar modelos multivariados de previsões para se alcançar retornos mais lucrativos.

E, no terceiro momento de análise, observou-se que os modelos univariados foram superiores nas previsões a curto (trimestre) e médio prazo (semestre) e os modelos multivariados foram superiores a longo prazo (ano). A rentabilidade da carteira Univariada a longo prazo (ano) foi negativa, podendo evidenciar a incapacidade destes modelos de previsão em projeções mais longas. Já nesse aspecto, a rentabilidade da carteira Multivariada foi superior, indicando que os modelos multivariados de previsão possuem superioridade em projeções mais longas de previsão.

Desta forma, nesse momento de análise, para se obter retornos mais lucrativos, o mais indicado seria usar modelos univariados em previsões de curto e médio prazo e modelos multivariados em previsões de longo prazo. Neste mesmo período as rentabilidades da carteira de mercado (Ibovespa) foram: $1,24 \%$ no trimestre; $-0,70 \%$ no semestre; e $-18,08 \%$ no ano.

Para solidificar as conclusões é necessário comparar o desempenho das carteiras ajustando-se aos seus respectivos riscos, para isso foi utilizado o Índice de Sharpe (IS). Assim, ao serem analisadas as variabilidades dos retornos das de cada portfólio, a carteira que apresentou o maior IS foi considerada a mais rentável. A tabela 5 apresenta estes resultados. 
Tabela 5. Comparação geral das carteiras - Índice de Sharpe.

\begin{tabular}{|c|c|c|c|}
\hline \multicolumn{4}{|c|}{$1^{\circ}$ momento de análise } \\
\hline & $1^{\circ}$ trimestre & $1^{\circ}$ semestre & 1 ano \\
\hline Índice de Sharpe/ Portfólio Univariado & $-0,7760$ & $-1,3163$ & $-0,3937$ \\
\hline Índice de Sharpe/Portfólio Multivariado & $-7,1725$ & $-4,2955$ & $-1,9433$ \\
\hline \multicolumn{4}{|c|}{$2^{\circ}$ momento de análise } \\
\hline & $1^{\circ}$ trimestre & $1^{\circ}$ semestre & 1 ano \\
\hline Î́ndice de Sharpe/ Portfólio Univariado & 1,8010 & 1,6793 & 1,1315 \\
\hline Índice de Sharpe/Portfólio Multivariado & 2,1779 & 1,5087 & 1,3427 \\
\hline \multicolumn{4}{|c|}{$3^{\circ}$ momento de análise } \\
\hline & $1^{\circ}$ trimestre & $1^{\circ}$ semestre & 1 ano \\
\hline Índice de Sharpe/ Portfólio Univariado & 1,3488 & 0,6511 & $-0,5631$ \\
\hline Índice de Sharpe/Portfólio Multivariado & 1,1236 & 0,0586 & 0,0431 \\
\hline
\end{tabular}

Fonte: Resultados da pesquisa.

Comparando-se o IS para os Portfólios Univariados e Multivariados nas três projeções de previsão, verificou-se, no primeiro momento de análise, que o Portfólio Univariado foi superior, visto que os prejuízos foram menores dadas as variâncias das carteiras. Já no segundo e terceiro momento de análise, observou-se mais uma vez que há uma tendência dos modelos univariados concederem retornos mais lucrativos nas projeções de curto prazo e dos modelos multivariados concederem retornos mais lucrativos nas projeções de longo prazo.

Portando, avaliando-se de forma geral todos os momentos, constata-se que as previsões baseadas em modelos multivariados tendem a fornecer aos investidores retornos superiores em investimentos de longo prazo (1 ano) e os modelos univariados tendem a fornecer aos investidores retornos superiores em investimentos de curto prazo ( 1 trimestre). Assim, usando informações contábeis em modelos de previsão, um investidor terá maior probabilidade de obter melhores retornos em estratégias de longo prazo, demonstrado assim, a relevância da informação. Todos os resultados que indicam contribuição dos índices contábeis para a melhoria dos retornos das ações são corroborados pelos resultados apresentados nos trabalhos de O'Halon (1991); Jindrichovsha (2001); Mahmood e Fatah (2001); Araujo Junior (2009); Carvalhal (2010); e Campos, Lamounier e Bressan (2011).

\section{CONCLUSÕES}

O principal objetivo desta pesquisa foi verificar se o uso de indicadores contábeis de liquidez, estrutura de capital e rentabilidade das firmas melhora a capacidade das previsões dos retornos das ações em relação às previsões feitas apenas a partir do histórico dos retornos, visando que os investidores em ações de empresas brasileiras de capital aberto obtenham melhores ferramentas para suas tomadas de decisões de acordo com a relevância da informação contábil. Desta forma, por meio de uma amostra de 20 empresas, foram especificados modelos univariados de previsão (ARIMA) apenas com o histórico dos retornos das ações, comparando-se posteriormente esses resultados com as previsões realizadas por modelos multivariados (VAR) com os índices contábeis como variáveis explicativas nos modelos.

Nas especificações dos modelos univariados observou-se a predominância de baixas defasagens, tanto na parte auto regressiva (AR), como principalmente na parte de Médias Moveis (MA). Isso permite concluir sobre a dependência dos erros derivados do modelo para se obter previsões significativas. Já nas especificações dos modelos multivariados, verificou-se que a ML foi o indicador que apresentou o maior número de casos (6 empresas) com significância estatística para prever o RET, seguido pelo ROE (5 empresas), GA (3 empresas), CE (3 empresas) e LC (1 empresa). O único índice que não se apresentou como o melhor pra prever o RET em alguma das empresas foi a PCT.

No primeiro momento de análise, as carteiras formadas pelos modelos univariados apresentaram 
melhores rentabilidades que as carteiras multivariadas, no entanto, ambas com rentabilidades negativas. Neste período de análise houve crise econômica mundial, comprometendo o mercado de capitais, o que pode ter causado a ineficiência dos modelos de previsão analisados. Com isso, pode-se concluir que neste período, uma opção seria investir em ativos livre de risco.

Já nos dois momentos seguintes de análise, tanto na comparação direta, quanto quando se considera os ajustes aos seus respectivos riscos (Índice de Sharpe), foi verificado, de forma geral, que as previsões baseadas em modelos multivariados tendem a fornecer aos investidores retornos superiores em investimentos de longo prazo (1 ano). Já os modelos univariados tendem a fornecer aos investidores retornos superiores em investimentos de custo prazo ( 1 trimestre). Assim, pode-se concluir que ao usar informações contábeis em modelos de previsão, um investidor terá maior probabilidade de obter melhores retornos com a negociação de ações em estratégias de longo prazo. Desta forma, não se rejeita a hipótese nula desta pesquisa, evidenciando-se que as informações contábeis são relevantes para o mercado acionário brasileiro, principalmente em estratégias de longo prazo. Todos esses resultados que indicam contribuição dos índices contábeis para a melhoria dos retornos das ações são corroborados pelos resultados apresentados nos trabalhos de O’Halon (1991); Jindrichovsha (2001); Mahmood e Fatah (2001); Araujo Junior (2009); Carvalhal (2010); e Campos, Lamounier e Bressan (2011).

Limitando-se às empresas analisadas, ao responder a questão de pesquisa "A análise de indicadores contábeis amplia a capacidade de previsão dos retornos de ações?" pode-se concluir que a inclusão de indicadores contábeis em modelos multivariados de previsão tem a competência de ampliar a capacidade de previsão dos retornos das ações, principalmente para previsões de longo prazo e quando as séries em análise possuem maior número de observações.

Como limitação, esta pesquisa não abordou os custos das operações de compra e venda de ações, tampouco os impostos incidentes sobre os ganhos, o que dependendo do volume de negociações, pode interferir nos retornos apresentados. Outra limitação se deve ao período de tempo analisado, que envolveu uma época de crise econômica mundial, interferindo nas variâncias dos retornos das ações, o que comprometeu os modelos de previsão. Sendo assim, apesar das séries possuírem mais de 50 observações, são indicadas séries mais extensas para melhores especificações e para não haver problemas relacionados à micronumerosidade.

Como sugestão para novas pesquisas, recomenda-se a ampliação da amostra, o que possibilitaria verificar se o comportamento continuaria o mesmo em empresas de países diferentes e com séries temporais mais longas. É sugerido também explorar outros índices contábeis derivados de outras demonstrações contábeis, tais como a Demonstração do Fluxo de Caixa (DFC) e a Demonstração do Valor Adicionado (DVA).

\section{REFERÊNCIAS}

ALEXANDER, D. R.; FALTA, M.; WILLETT, R. J. Using Forecasting Criteria to Identify Value Relevance in the Relationship Between Accounting Numbers and Market Value. ABACUS, Vol. 48, No. 3, 2012

ARAÚJO JÚNIOR, J. B. Modelagem do processo de análise fundamentalista de uma empresa com a utilização de vetores auto-repressivos. Dissertação apresentada para a obtenção do título de Mestre em Ciências Contábeis do Programa Multiinstitucional e Inter-regional de Pós-Graduação em Ciências Contábeis da Universidade Federal de Brasília, da Universidade Federal da Paraíba e da Universidade Federal do Rio Grande do Norte: Brasília. 2009.

BALL, R.; BROWN, P. (1968). An empirical evaluation of accounting income numbers. Journal of Accounting Research, 6(2):159-178.

BAR-YOSEF, S.; CALLEN, J. F.; LIVNAT, J. (1987). Autoregressive Modeling of Earnings-Investment Causality. The Journal of Finance. vol. XLII, no. 1 Mar 1987.

BARTH, Mary E.; BEAVER, William H.; LANDSMAN, Wayne R. The relevance of the value- relevance literature for financial accounting standard setting: another view. Journal of Accounting and Economics. v. 31, p. 77-104. 2001.

BEAVER,W. H. (1968). The information content of annual earnings announcements. 
Journal of Accounting Research, 6(2):67-92.

; MCANALLY, Mary Lea; STINSON, Christopher H. The information content of earnings and prices: A simultaneous equations approach, Journal of Accounting and Economics, v. 23, n. 1, p. 53-81, May, 1997.

BODIE. Z.; KANE, A.; MARCUS, A. Investments 5th ed. Boston: McGraw - Hill/Irwin, 2002.

BRUGNI, T. V; FÁVERO, L. P. L; FLORES, E. S; BEIRUTH, A. X. O vetor de causalidade entre lucro contábil e preço das ações: existem incentivos para a informação contábil seguir o preço no brasil? .Revista Contabilidade Vista \& Revista, ISSN 0103-734X, Universidade Federal de Minas Gerais, Belo Horizonte, v. 26, n. 1, p. 79-103, jan./abr. 2015.

BUENO, R. L. S. Econometria de séries temporais. 1ª edição. São Paulo: Cengage Learning, 2011. 299 p.

CAMPOS, O. V; LAMOUNIER, W. M; BRESSAN, V. G. F. Lucro e os Retornos das Ações: Avaliação da Relevância da Informação Contábil. XXXV Encontro da ANPAD. Rio de Janeiro. 2011.

CARVAlHaL, R. B. D. Causalidade Entre os Retornos Contábeis e os Retornos do Mercado de Ações Brasileiro. XXXIV Encontro da ANPAD. Rio de Janeiro. 2010.

COMITÊ de Pronunciamentos Contábeis. Pronunciamento Técnico CPC 00: Estrutura Conceitual para a Elaboração e Apresentação das Demonstrações Contábeis. Brasília: 11 de janeiro de 2008. Disponível em: $<$ http://www.cpc.org.br>. Acessado em: 12/08/2009.

COSTA, F.M.; COSTA, A.C.O.; LOPES, A.B. Conservadorismo em cinco países da América do Sul. Revista de Contabilidade \& Finanças da Universidade de São Paulo, São Paulo, n. 41, p. 7-19, maio/ago. 2006.

COSTA Jr, N. C. A; MEURER, R; CUPERTINO, C.M. Existe Alguma Relação entre Retornos Contábeis e Retornos do Mercado de Ações no Brasil? Revista Brasileira de Finanças 2007 Vol. 5, No. 2, pp. 233-245 C 2004. Sociedade Brasileira de Finanças.

ENDERS, W. Applied econometric time series. New York: John Wiley, 2003.

FOSTER, G. Financial Statement Analysis. $2^{\text {nd }}$ ed. Prentice Hall, Englewood Cliffs, (1986).

FRANCIS, Jennifer; SCHIPPER, Katherine. Have financial statements lost their relevance? Journal of Accounting Research, v. 37, n. 2, p. 319-352, 1999.

GALDI, F. C; LOPES, A. B. Relação de longo prazo e causalidade entre o lucro contábil e o preço das ações: evidências do mercado latino-americano. Revista de Administração, São Paulo, v.43, n.2, p.186-201, abr./ maio/jun. 2008

GRANGER, C. W. J. Investigating casual relations by econometric models and cross-spectral methods. Econometrica, 37(3):424-438., 1969.

GUJARATI, D. N. Econometria Básica. 4a edição. Makron Books do Brasil Editora Ltda. São Paulo. 2006.

HOLDEN, K; PEEL, D.A; THOMPSON, J.L. Economic forecasting: an introduction. Cambridge University Press. 1990

JINDRICHOVSKA, I. The relationship between accounting numbers and returns: some empirical evidence from the emerging market of the Czech Republic. The European Accounting Review. 10:1, 107-131. 2001 .

LAMOUnier, W. M. O Comportamento dos Preços no Mercado Spot de Café: Uma Análise dos Domínios do Tempo e da Frequência. Viçosa: UFV. Tese (Doutorado em Economia Rural) - Universidade Federal de Viçosa, 2001.

MATARAZZO, D. C. Análise financeira de balanços: abordagem básica e gerencial. 6. ed. São Paulo: Atlas, 2003. 
MARTIKAINEN, T.; PUTTONEN V. Dynamic linkages between stock prices, accrual earnings and cash flows: a co-integration analysis. Annals of Operations Research, 45, 1993. 319-332

MAHMOOD, W. M. W.; FATAH, F. S. A. Multivariate Causal Estimates of Dividend Yields, Price Earning Ratio and Expected Stock Returns: Experience from Malaysia. 15th Annual Conference on Pacific Basin Finance, Economic, Accounting and Management in Equatorial Hotel, Ho Chi Minh City, Vietnam on the 20 -21 st July, 2007.

O'HANLON, J. The relationship in time between annual accounting returns and annual stock market returns in the U.K. Journal of Business Finance and Accounting, 18(3). (1991).

OLIVEIRA, M. A.; MONTINI, A. A.; BERGMANN, D. R. Previsão de retornos de ações dos setores Financeiro, de Alimentos, Industrial e de Serviços, por meio de RNA e modelos Arima-Garch. Revista de Administração Mackenzie - RAM. Volume 9, n. 1, 2008, p. 130-156.

PHILLIPS, P.; PERRON, P. Testing for a unit root in time series regression. Biometrika, v. 75, n. 2, p. 335-346, 1988.

PINDYCK, R.S.; RUBINFELD, D.L. Econometria: Modelos e previsões. 4 ed. Rio de Janeiro: Ed. Campos. 2004.

SONZA, I. B.; KLOECKNER, G. O. Co-integração entre o lucro contábil e o preço das ações negociadas pela bovespa: um estudo empírico. IX Encontro brasileiro de finanças (2009).

TSWEI, K. Is transaction price more value relevant compared to accounting information? An investigation of a time-series approach. Pacific-Basin Finance Journal. Volume 21, Issue 1, January. 2013.

VAN DOORNIK, B. F. N. Modelagem econométrico-financeira de uma empresa baseada em vetores autoregressivos: uma aplicação à PETROBRAS S.A. Dissertação apresentada ao mestrado em Administração da Universidade Federal de Brasília como requisito parcial à obtenção do grau de mestre: Brasília. 2007.

WATTS, R. L.; ZIMMERMAN, J. L. Positive accounting theory. Englewood Cliffs, N.J.: Prentice-Hall. 1986. 